\title{
Comparative study of nitrogen implantation effect on mechanical and tribological properties of $\mathrm{Ti}-6 \mathrm{Al}-4 \mathrm{~V}$ and $\mathrm{Ti}-10 \mathrm{Zr}-10 \mathrm{Nb}-5 \mathrm{Ta}$ alloys
}

\author{
Stéphanie Carquigny ${ }^{1}$, Jamal Takadoum ${ }^{1, *}$, and Steliana Ivanescu ${ }^{2}$ \\ ${ }^{1}$ Institut FEMTO-ST (CNRS, UFC, UBFC, ENSMM, UTBM) ENSMM, 26 rue de l'Epitaphe, 25030 Besançon, France \\ ${ }^{2}$ R\&D Consulting \& Services, Calea Rahovei str. no. 266-268, Sector 5, Bucharest, Romania
}

Received: 15 May 2018 / Received in final form: 6 December 2018 / Accepted: 28 January 2019

\begin{abstract}
The effect of nitrogen implantation on mechanical and tribological properties of Ti-6Al-4V and Ti-10Zr-10Nb-5Ta alloys was studied. Increasing implantation dose from $1 \times 10^{16} \mathrm{~N}^{+} / \mathrm{cm}^{2}$ to $2 \times 10^{17} \mathrm{~N}^{+} / \mathrm{cm}^{2}$ leads to increase gradually both hardness and Young's modulus. The results show that implantation of $2 \times 10^{17}$ $\mathrm{N}^{+} / \mathrm{cm}^{2}$ allowed to double the value of Young's modulus and to triple the value of hardness. Friction tests that have been conducted against 100Cr6 steel and alumina balls showed that tribological behavior of the two alloys depend on the nature of the counterpart material and is strongly affected by the implanted dose of nitrogen.
\end{abstract}

\section{Introduction}

Due to the formation of very stable, continuous, highly adherent and protective oxide on their surface [1,2], titanium alloys show an excellent resistance to corrosion. In addition, since they are biocompatible and have low density and high specific strength, they are being increasingly used for medical implants.

Ti-6Al-4V is the most popular alloy that is used in numerous industrial and medical applications. Nevertheless, since the toxicity of aluminum and vanadium has been reported by several studies [3,4], new $\mathrm{Al}$ and $\mathrm{V}$ free betatype titanium based alloys have been developed. These new materials contain non-toxic elements such niobium, zirconium and tantalum that allow the formation of chemically stable passivating film. Nb stabilizes $\mathrm{TiO}_{2}$ while $\mathrm{Zr}$ and $\mathrm{Ta}$ form $\mathrm{ZrO}_{2}$ and $\mathrm{Ta}_{2} \mathrm{O}_{5}$ which are known to be very chemically stable and very protective $[5,6]$.

Beta-type titanium based alloys with various compositions have been elaborated and studied by numerous researchers: Ti-29Nb-13Ta-4Zr [7], Ti-10Zr-10Nb-5Ta [8], Ti-Nb [9,10], Ti-15Mo-3Nb-3Al [11], Ti6-Al7-Nb [12], Ti-6Al-4V-1Zr [13]. In all these studies, the authors reported the high potential of these materials to be used for medical implants.

Generally titanium based alloys are used after a specific coating treatment to enhance their ability to form chemical strong bonds with living bone [13-16]. Among all the techniques of surface treatment, ion implantation offers the advantages to modify both mechanical and chemical properties of the treated materials without affecting the

\footnotetext{
* e-mail: Jamal.Takadoum@ens $2 \mathrm{~m} . \mathrm{fr}$
}

surface finish. Several studies have focused on the modifications induced by nitrogen implantation in titanium and titanium alloys and all of them reported an improvement of mechanical properties [17-19]. In the case of Ti- $6 \mathrm{Al}-4 \mathrm{~V}$, the improvement of mechanical properties after nitrogen implantation was correlated with the precipitation of hard $\delta$-TiN layer and the apparition of compressive elastic stress in the residual $\alpha-\mathrm{Ti}_{1-x} \mathrm{~N}_{x}$ matrix [20]. In [21], the authors reported that nitrogen implantation into Ti-6Al-4V enhanced its corrosion resistance in $0.6 \mathrm{M} \mathrm{NaCl}$ solution. However, nitrogen ion implantation at high doses may be detrimental with regards to corrosion [22] and the best corrosion resistance has been achieved for an optimum dose of $1 \times 10^{17} \mathrm{~N}^{+} / \mathrm{cm}^{2}$ [23].

In another study [24], ZrNbTaTiW films, prepared by magnetron sputtering deposition, were implanted with increasing doses of nitrogen ranging from $1 \times 10^{17}$ ions $/ \mathrm{cm}^{2}$ to $4 \times 10^{17}$ ions $/ \mathrm{cm}^{2}$ and characterized by nanoindentation tests. It has been found that hardness and Young's modulus increase gradually with increasing implantation dose and reach maximum values of $13.5 \mathrm{GPa}$ (hardness) and $178.9 \mathrm{GPa}$ (Young's modulus) after an implantation dose of $2 \times 10^{17}$ ions $/ \mathrm{cm}^{2}$. This increase of mechanical properties was attributed to the formation of a mixed layer of oxides and nitrides: TaN, TiN, $\mathrm{NbN}, \mathrm{ZrO}_{2}$. The authors showed also that with further increasing of implantation doses, the hardness and Young's modulus slightly decrease due to over-stoichiometric nitrogen ions or re-sputtering effect.

In a previous paper [8], we have conducted a comparative study of corrosion and tribocorrosion between Ti-6l-4V and Ti-10Zr-10Nb-5Ta alloy and we have shown that the latter has better electrochemical behavior (rate of passivation and resistance to corrosion). In the present study, we report new results concerning the effect of 

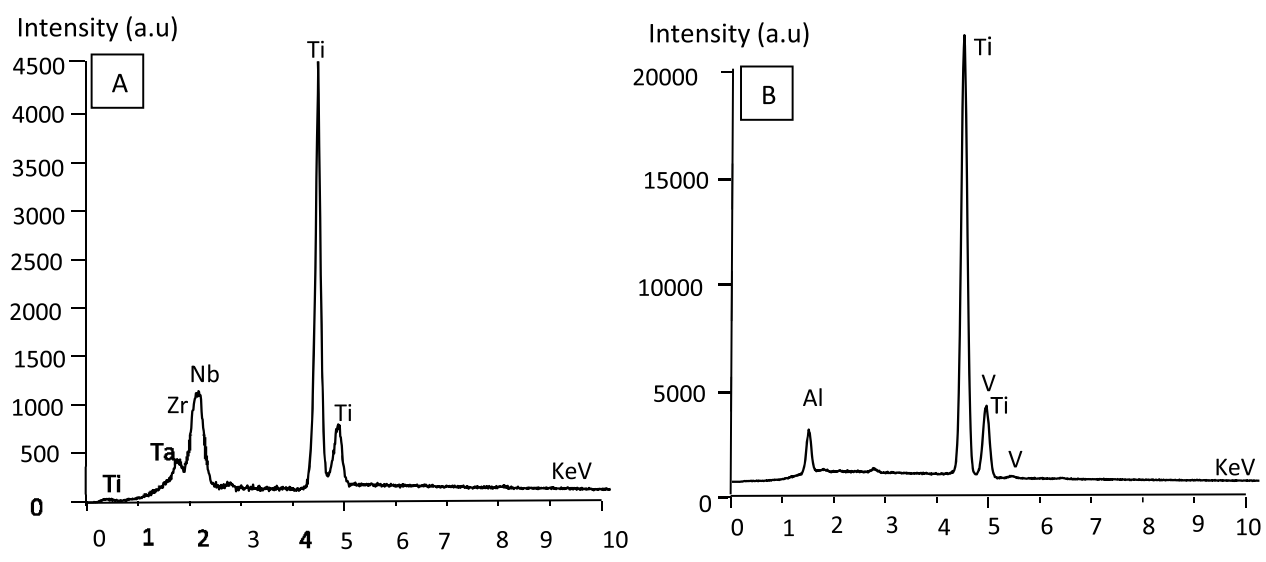

Fig. 1. EDX spectrums of Ti-10Zr-10Nb-5Ta (A) and Ti-6Al-4V (B) alloys.

Table 1. Implantation parameters. $R_{p}$ is the mean projected range of ions, $\Delta R_{p}$ is the standard deviation of the distribution and $C\left(R_{p}\right)$ is the maximum of nitrogen concentration at depth $R_{p}$.

\begin{tabular}{llllll}
\hline Implanted material & Energy $(\mathrm{KeV})$ & Implanted nitrogen dose $\left(\right.$ ions $\left./ \mathrm{cm}^{2}\right)$ & $R_{p}(\mathrm{~nm})$ & $\Delta R_{p}(\mathrm{~nm})$ & $C\left(R_{p}\right)$ \\
\hline & 50 & $1 \times 10^{16}$ & 94 & 41 & $1.9 \times 10^{-2}$ \\
Ti-10Zr-10Nb-5Ta & 50 & $5 \times 10^{16}$ & 94 & 41 & $9.5 \times 10^{-2}$ \\
& 50 & $2 \times 10^{17}$ & 94 & 41 & $38 \times 10^{-2}$ \\
& 50 & $1 \times 10^{16}$ & 88 & 35 & $1.7 \times 10^{-2}$ \\
Ti-6Al-4V & 50 & $5 \times 10^{16}$ & 88 & 35 & $8.5 \times 10^{-2}$ \\
& 50 & $2 \times 10^{17}$ & 88 & 35 & $34 \times 10^{-2}$ \\
\hline
\end{tabular}

nitrogen implantation on mechanical and tribological properties of these alloys when sliding against 100Cr6 steel or alumina.

\section{Materials and methods}

Ti-6Al-4V and Ti-10Zr-10Nb-5Ta alloys were respectively obtained from Stainless (France) and R\&D Consulting \& Services (Bucharest, Romania).

Samples of the two alloys were examined using X-ray microanalysis (EDX) facility. The spectra of the analysis are shown in Figure 1A and $\mathrm{B}$ and the chemical compositions deduced from these analyses are as follows: Ti-6Al-4V (Ti: $90.46 \%, \quad$ Al:7.56\%, V:1.98\%), Ti-10Zr-10Nb-5Ta (Ti: $72.2 \%$, Zr: $10.8 \%$, Nb:11.2\%, Ta:5.8\%).

Metal samples were first grinded with $\mathrm{SiC}$ papers down to grad 1000 and then polished with diamond solution down to $1 \mu \mathrm{m}$. Ultimately, they were cleaned in an ultrasonic bath and rinsed with ethanol. Ion implantations were conducted at $50 \mathrm{KeV}$ at various doses $\left(1 \times 10^{16} \mathrm{~N}^{+} / \mathrm{cm}^{2}, 5 \times 10^{16} \mathrm{~N}^{+} / \mathrm{cm}^{2}\right.$ and $2 \times 10^{17}$ $\mathrm{N}^{+} / \mathrm{cm}^{2}$ ) using IRMA implanter of the CSNSM (Orsay, France) [25].

Since the nitrogen concentration may be approximated by a Gaussian, the parameters of implantation calculated using the TRIM program $[26,27]$ are given in Table 1.
Hardness and Young's modulus values were obtained using a CSM Instruments Nanoindention Tester. Friction tests have been conducted using an experimental device constituted by a ball-on-disc nano-tribometer that has been presented in previous papers [28,29]. Tests were carried out at ambient air and room temperature under an applied load of $100 \mathrm{mN}$. The riders were spheres of polycrystalline alumina (hardness: $1650 \mathrm{HV}$ ) or $100 \mathrm{Cr} 6$ steel (hardness: $720 \mathrm{HV}$ ) with a diameter of $1.5 \mathrm{~mm}$. The motion was reciprocating with a frequency of $0.35 \mathrm{~Hz}$. The length of the sliding distance was $1 \mathrm{~mm}$ and the test duration was 4.75 minutes corresponding to a total sliding distance of $180 \mathrm{~mm}$ and 100 cycles.

\section{Results and discussion}

\subsection{Hardness and young's modulus measurements}

Figures 2 and 3 show values of hardness and Young modulus of Ti-10Zr-10Nb-5Ta and Ti-6Al-4V alloys before and after implantation of various doses of nitrogen: $1 \times 10^{16}$ $\mathrm{N}^{+} / \mathrm{cm}^{2}, 5 \times 10^{16} \mathrm{~N}^{+} / \mathrm{cm}^{2}$ and $2 \times 10^{17} \mathrm{~N}^{+} / \mathrm{cm}^{2}$.

For Ti-10Zr-10Nb-5Ta, implantation of the highest dose allows to (almost) double the value of Young modulus and to triple the value of hardness. These values jump from respectively from $85 \mathrm{GPa}$ and $480 \mathrm{HV}$ for the unimplanted material to $140 \mathrm{GPa}$ and $1350 \mathrm{HV}$ after implantation of $2 \times 10^{17} \mathrm{~N}^{+} / \mathrm{cm}^{2}$. For Ti-6Al-4V, the increase of hardness 
$\underline{A}$

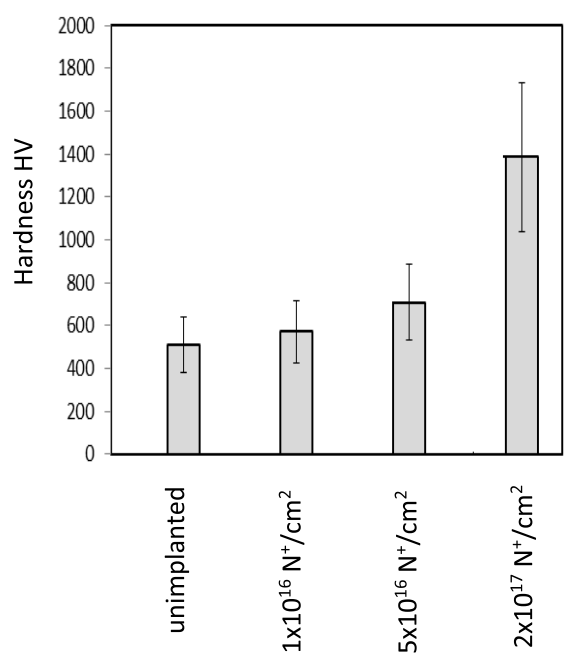

$\underline{B}$

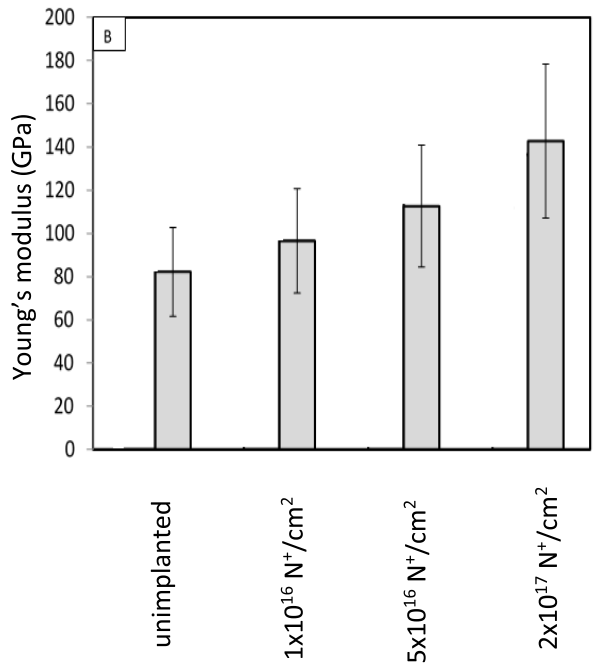

Fig. 2. Hardness (A) and Young's modulus (B) of Ti-10Zr-10Nb-5Ta unimplanted and implanted with various doses of nitrogen.

$\underline{\mathrm{A}}$

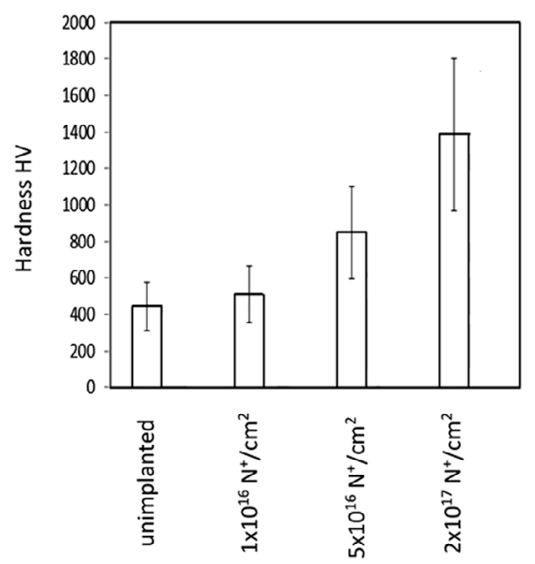

$\underline{B}$

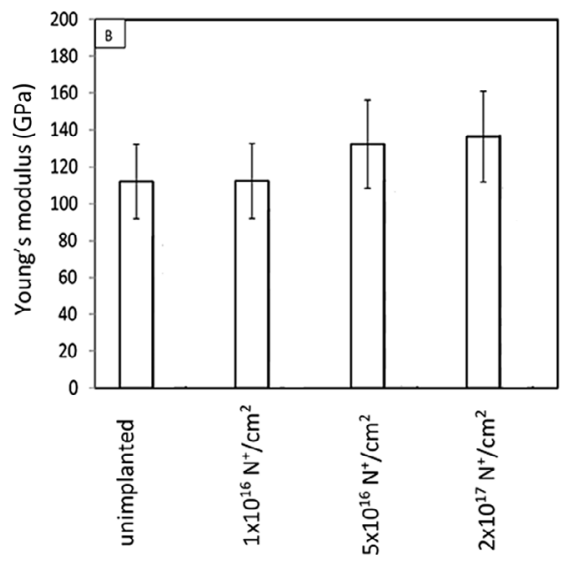

Fig. 3. Hardness (A) and Young's modulus (B) of Ti-6Al-4V alloys unimplanted and implanted with various doses of nitrogen.

after ion implantation is comparable to the one observed for Ti-10Zr-10Nb-5Ta whereas Young's modulus increases more slowly.

It appears clearly that mechanical properties of the alloys increase gradually with increasing implantation dose. This result may be explained by the formation of nitrides such as, e.g., TiN, $\mathrm{ZrN}$, TaN, NbN, AlN as has been reported in previous works $[5,6,30,31]$. Theses phases have been also identified by XPS analysis in the present study. Figure 4 shows N1s region for Ti-10Zr-10Nb-5Ta alloy. The figure shows an important peak that situates around $396 \mathrm{eV}$. It corrspond to $\mathrm{Zr}-\mathrm{N}$ and $\mathrm{Ti}-\mathrm{N}$ bonds whose binding energies are very close each other and situates at $396.7 \mathrm{eV}$ for $\mathrm{TiN}$ and $396.5 \mathrm{eV}$ for $\mathrm{ZrN}$. In addition to this first peak, one can see two shoulder peaks that situates at $397 \mathrm{eV}$ and $397.8 \mathrm{eV}$. They correspond respectively to TaN and $\mathrm{NbN}$.

Figure 5 shows the Al2p spectrum. On can see that Al2p peak corresponding to $\mathrm{Al}-\mathrm{N}$ bond is splitted into a higher intensity peak corresponding to $\mathrm{Al} 2 \mathrm{p} 3 / 2$ at $73.7 \mathrm{eV}$ binding

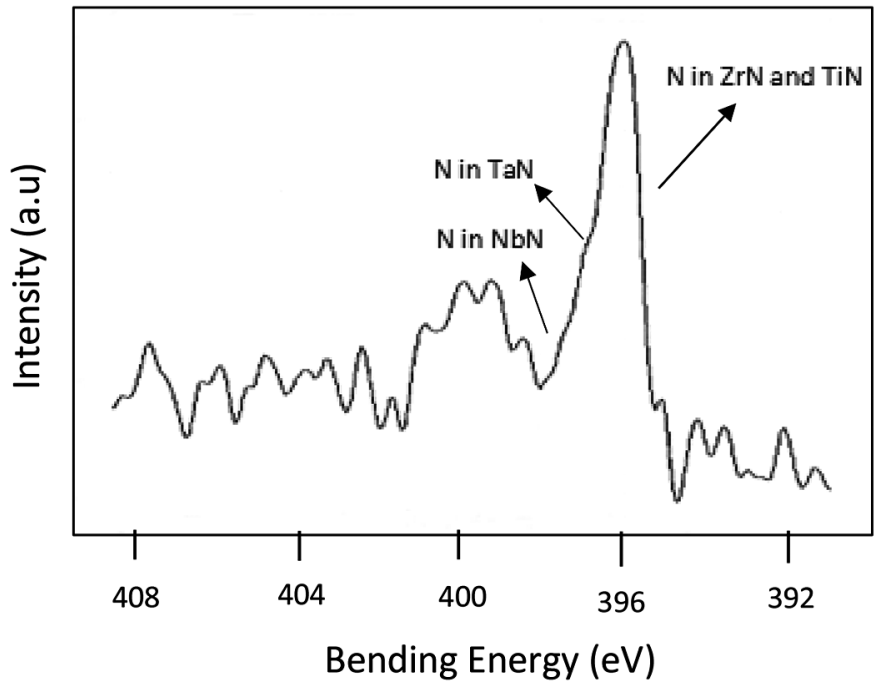

Fig. 4. XPS spectra of N1s region for nitrogen implanted Ti-10Zr-10Nb-5Ta alloy. 


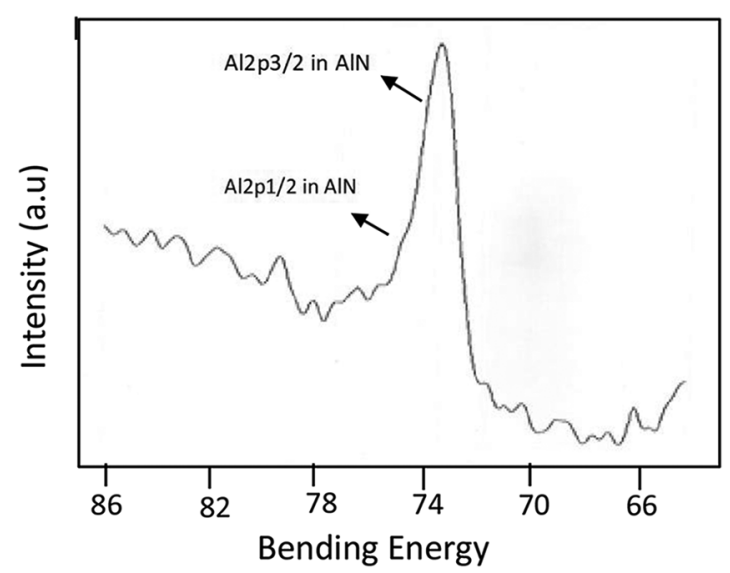

Fig. 5. XPS spectra of $\mathrm{Al} 2 \mathrm{p} 3 / 2$ and $\mathrm{Al} 2 \mathrm{p} 1 / 2$ in $\mathrm{Al}-\mathrm{N}$ bond for nitrogen implanted Ti-6Al-4V.
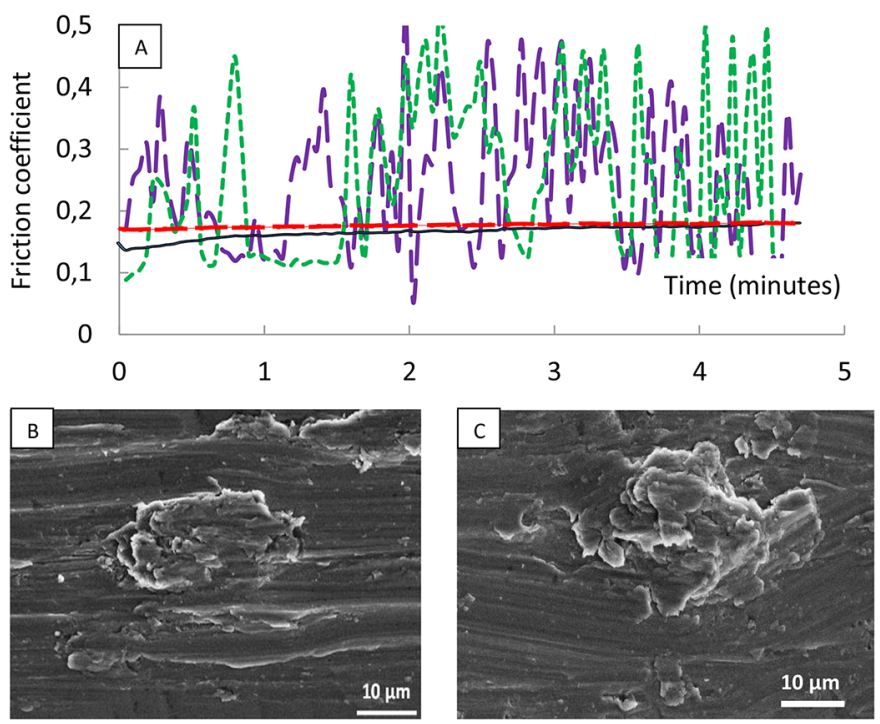

Fig. 6. (A) Variation of friction coefficient with time for Ti-10Zr-10Nb-5Ta when sliding against an alumina ball. (B) and (C) show respectively wear debris on the track for the unimplanted specimen and the specimen implanted with the lowest dose. Unimplanted (ローローーロー), implanted with $1 \times 10^{16} \mathrm{~N}^{+} / \mathrm{cm}^{2}$ ( - - - - - implanted with $5 \times$ $10^{16} \mathrm{~N}^{+} / \mathrm{cm}^{2}(-\cdots-\cdots-)$, implanted with $2 \times 10^{17} \mathrm{~N}^{+} / \mathrm{cm}^{2}$ ( $)$.

energy and a lower intensity peak that appears as a shoulder peak corresponding to Al2p1/2 at $74.8 \mathrm{eV}$ binding energy position.

\subsection{Friction tests}

\subsubsection{Ti-10Zr-10Nb-5Ta alloy}

The variation of friction coefficient during sliding against an alumina ball is shown in Figure $6 \mathrm{~A}$. One can see that the evolution of friction coefficient of the unimplanted specimen and the specimen implanted with the lowest dose of nitrogen show important and rapid oscillations indicating seizure and surface wear.

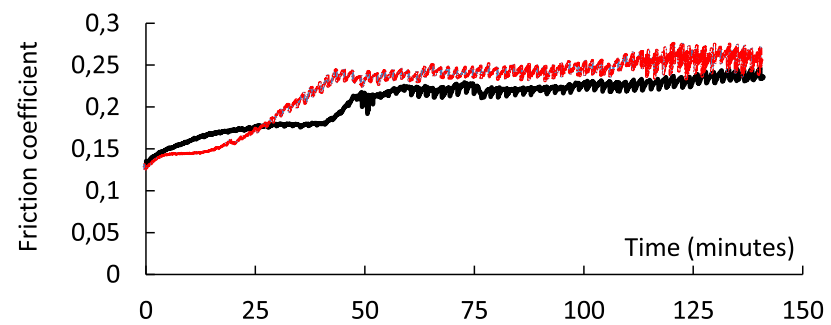

Fig. 7. Long duration friction tests conducted on the two higher implanted samples: $5 \times 10^{16} \mathrm{~N}^{+} / \mathrm{cm}^{2}(\ldots \ldots-\cdots-)$ and $2 \times 10^{17} \mathrm{~N}^{+} / \mathrm{cm}^{2}$ (—). The experimental conditions are specified in Section 2 .
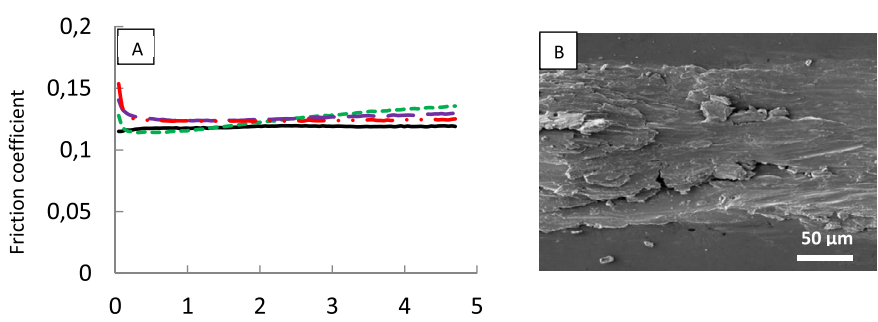

Fig. 8. (A) Variation of friction coefficient with time for Ti-10Zr-10Nb-5Ta when sliding against a 100Cr6 steel ball. (B) shows metal transfer from the steel ball on the surface

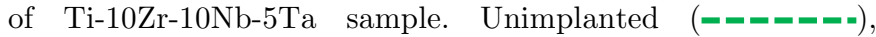
implanted with $1 \times 10^{16} \mathrm{~N}^{+} / \mathrm{cm}^{2}$ (—- implanted with $5 \times 10^{16} \mathrm{~N}^{+} / \mathrm{cm}^{2}$ (_ : - " ), implanted with $2 \times 10^{17} \mathrm{~N}^{+} / \mathrm{cm}^{2}$ (—). The experimental conditions are specified in Section 2.

The friction coefficient oscillates rapidly between 0.1 and 0.5 and examination of the wear track reveals material removal (Fig. $6 \mathrm{~B}$ and $\mathrm{C}$ ). The specimens implanted with higher doses $\left(5 \times 10^{16} \mathrm{~N}^{+} / \mathrm{cm}^{2}\right.$ and $\left.2 \times 10^{17} \mathrm{~N}^{+} / \mathrm{cm}^{2}\right)$ did not suffer any wear and they show similar value of friction coefficient that is stable during sliding and situates between 0.14 and 0.16 (Fig. 6A).

Additional tests have been performed on the specimens implanted with the highest doses during 150 min instead of 5 min. The evolution of friction coefficient with time is presented in Figure 7. Friction coefficient increases gradually during sliding passing from 0.13 to 0.23 . It still shows lower values than those obtained for the unimplanted specimen or the specimen implanted with $1 \times 10^{16}$ $\mathrm{N}^{+} / \mathrm{cm}^{2}$. In addition, the strong oscillations indicating seizure between the rubbing surfaces does not appear indicating a good resistance to wear. Wear rate has been measured at the end of the tests and the obtained results show that wear is much lower for samples implanted with the highest doses in comparison with the unimplanted specimen or the one implanted with the lowest dose. Indeed, wear rate is of $4 \times 10^{-7} \mathrm{~mm}^{3} \mathrm{~N}^{-1} \mathrm{~m}^{-1}$ and $2 \times 10^{-6}$ $\mathrm{mm}^{3} \mathrm{~N}^{-1} \mathrm{~m}^{-1}$ respectively for the specimen implanted with $2 \times 10^{17} \mathrm{~N}^{+} / \mathrm{cm}^{2}$ and $5 \times 10^{16} \mathrm{~N}^{+} / \mathrm{cm}^{2}$ whereas it is in the range of $0.45 \times 10^{-4}$ to $1.38 \times 10^{-4} \mathrm{~mm}^{3} \mathrm{~N}^{-1} \mathrm{~m}^{-1}$ for the unimplanted specimen and for the one implanted with $1 \times 10^{16} \mathrm{~N}^{+} / \mathrm{cm}^{2}$.

Friction tests conducted against the $100 \mathrm{Cr} 6$ steel balls (Fig. 8A) show that ion implantation affects neither 

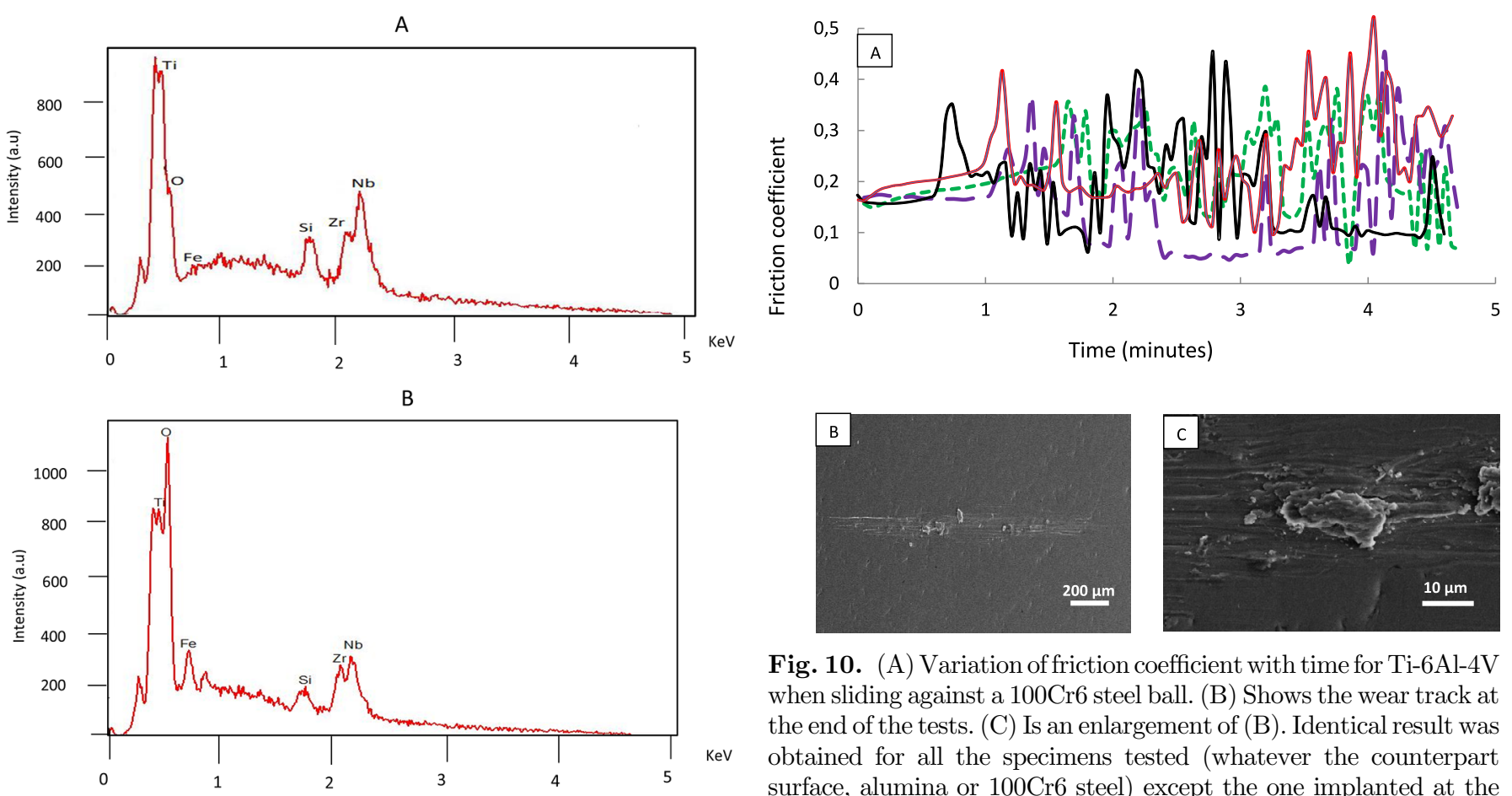

Fig. 10. (A) Variation of friction coefficient with time for Ti-6Al-4V when sliding against a 100Cr6 steel ball. (B) Shows the wear track at the end of the tests. (C) Is an enlargement of (B). Identical result was obtained for all the specimens tested (whatever the counterpart surface, alumina or $100 \mathrm{Cr} 6$ steel) except the one implanted at the

Fig. 9. EDX spectrums outside (A) and inside (B) the wear track on Ti-10Zr-10Nb-5Ta after sliding against a steel ball. Material transfer $(\mathrm{Fe})$ from the ball has been detected inside the wear track.

friction coefficient nor wear of the sample. Identical friction coefficient value of about 0.12 was obtained for all the specimen tested and no wear has been detected. Material transfer from the steel ball on the implanted titanium alloy sample was observed (Fig. 8B). Indeed $\mathrm{X}$-ray microanalysis spectra shows the presence of iron on the transferred material layer (Fig. 9B). One can also see the presence of a high peak of oxygen indicating that a probable oxidation of iron takes place during friction leading to the formation of iron oxide on the surface of the Ti-10Zr-10Nb-5Ta alloy.

\subsubsection{Ti-6Al-4V alloy}

Whatever the specimen tested (implanted or unimplanted), during sliding against $100 \mathrm{Cr} 6$ ball, friction coefficient values showed oscillating pattern (stick slip) and varied between 0.05 and 0.35 indicating that seizure occurs at the interface (Fig. 10A). The surface of the material suffers significant wear. It seems that adhesive wear takes place leading to an important material removal (Fig. 10B and C). The wear debris generated during wear may act as abrasive material leading to increase material loss during the wear test.

When sliding against the alumina ball, we obtain identical results as those found in the case of the $100 \mathrm{Cr} 6$ steel ball except for the specimen implanted with the highest dose of $2 \times 10^{17} \mathrm{~N}^{+} / \mathrm{cm}^{2}$. For this specimen friction coefficient shows a low value that increases slowly during sliding passing from 0.15 (starting value test) to 0.25 (end of test) (Fig. 11). In addition no wear has been observed on the surface of the material.

In this case, no wear was detected.

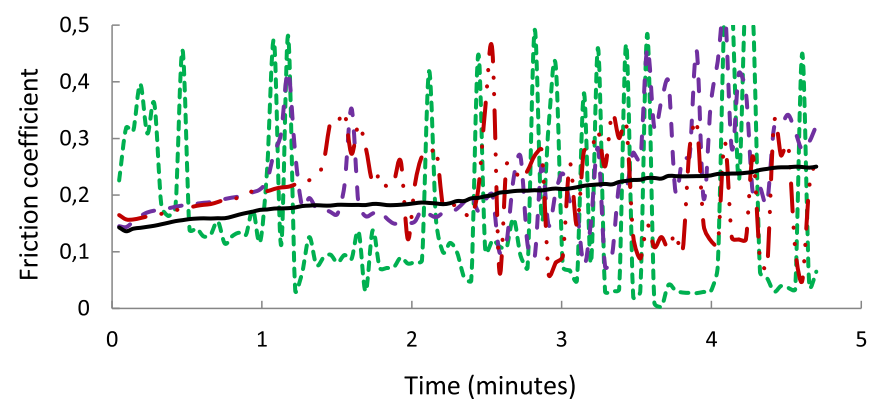

Fig. 11. Variation of friction coefficient with time for Ti-6Al-4V when sliding against an alumina ball. Unimplanted (-ーーーーーー), implanted with $1 \times 10^{16} \mathrm{~N}^{+} / \mathrm{cm}^{2}$ (-ーーーーーー), implanted with $5 \times 10^{16} \mathrm{~N}^{+} / \mathrm{cm}^{2}(\ldots-\cdots)$, implanted with $2 \times 10^{17} \mathrm{~N}^{+} / \mathrm{cm}^{2}$

$(\longrightarrow)$. The experimental conditions are specified in Section 2.

Comparison between Ti-6Al-4V and Ti-10Zr-10Nb-5 Ta alloys makes it possible to say that Ti- $6 \mathrm{Al}-4 \mathrm{~V}$ presents the worst tribological behavior when sliding against $100 \mathrm{Cr} 6$ steel. This behavior can be explained by tribochemical reactions that takes place between Ti- $6 \mathrm{Al}-4 \mathrm{~V}$ and counterpart material leading to adhesive wear and high friction coefficient as has been reported in [32]. Identical result has been pointed out in [33] where the authors studied tribological behavior of TiAl intermetallics when sliding against steel or alumina. The presence of aluminium is probably the main cause that leads to the formation of strong jonctions at the interface between the rubbing surfaces and consequently to adhesive wear and high friction coefficient. Indeed, this behavior may be attributed to the high chemical activity of aluminum and to its low melting point that may be reached during friction test [34]. 


\section{Conclusion}

Ti-6Al-4V and Ti-10Zr-10Nb-5Ta alloys were implanted with nitrogen at three doses $1 \times 10^{16} \mathrm{~N}^{+} / \mathrm{cm}^{2}, 5 \times 10^{16} \mathrm{~N}^{+} /$ $\mathrm{cm}^{2}$ and $2 \times 10^{17} \mathrm{~N}^{+} / \mathrm{cm}^{2}$. The effect of ion implantation on mechanical and tribological properties of the materials was studied. The following is a summary of the results obtained: - Nitrogen ion implantation leads to increase hardness and Young's modulus for the two materials in quite same way. - During friction tests, whatever the counter ball (100Cr6 steel or alumina), unimplanted and low-fluence implanted Ti-6Al-4V alloy $\left(1 \times 10^{16} \mathrm{~N}^{+} / \mathrm{cm}^{2}\right.$ and $\left.5 \times 10^{16} \mathrm{~N}^{+} / \mathrm{cm}^{2}\right)$ show a poor tribological behavior, characterized by an important stick-slip during friction and an important wear by material removal. The specimen implanted at the highest dose of $2 \times 10^{17}$ $\mathrm{N}^{+} / \mathrm{cm}^{2}$ shows a low and stable friction coefficient and a good resistance to wear when sliding against alumina ball whereas high friction coefficient and wear were obtained when sliding against $100 \mathrm{Cr} 6$ steel ball.

- Implanted and unimplanted Ti-10ZR-10Nb-5Ta alloy present a low friction coefficient when sliding against a steel ball. In contrast when sliding against an alumina ball unimplanted specimen and the specimen implanted at $1 \times 10^{16} \mathrm{~N}^{+} / \mathrm{cm}^{2}$ adhere to alumina leading to a high friction coefficient and an important wear whereas implanted specimens at $5 \times 10^{16} \mathrm{~N}^{+} / \mathrm{cm}^{2}$ and $2 \times 10^{17}$ $\mathrm{N}^{+} / \mathrm{cm}^{2}$ did not suffer any wear and present low and stable friction coefficient without stick slip.

This work was supported by OSEO (project FIMED under contract No A0907009I).

\section{Author contribution statement}

S. Ivanescu has elaborated and provided the Ti-10Zr-10Nb-5Ta alloy specimens. S. Carquigny has conducted the tribological tests. J. Takadoum has conducted the surface analysis and wrote the paper.

\section{References}

1. M.J. Donachie, Titanium: A technical guide (ASM International, 2000)

2. L.H. Hihara, R.P.I. Adler, R.M. Latanision (editors), Environnemental degradation of advanced and traditional engineering materials (CRC Press, 2014)

3. S. Sanchez-Iglesias, E. Mendez-Alvarez, J. Iglesias-Gonzalez, A. Munoz-Patino, I. Sanchez-Sollero, J.L. LabandeiraGarcia, R. Soto-Otero, J. Neurochem. 109, 879 (2009)

4. H. Mishibata (editor), Vanadium Biochemical and Molecular Biological Approaches (Springer, 2012)

5. E. Vasilescu, P. Drob, D. Ionita, S. Ivanescu, C. Vasilescu, Int. J. Environ. Sci. Dev. 1, 31 (2010)

6. N.S. More, N. Diomidis, S.N. Paul, M. Roy, S. Mischler, Mater. Sci. Eng. C 31, 400 (2011)

7. T. Akahori, M. Niinomi, M. Nakai, T. Kasuga, M. Ogawa, Mater. Trans. 49, 365 (2008)
8. J. Takadoum, J. El Mansouri, S. Ivanescu, D. Stanciu, in 2012 MRS Spring Meeting, San Francisco, CA, Materials Research Society mrss12-1464-rr 06-06

9. B. Piotrowski, AA. Baptista, E. Patoor, P. Bravetti, A. Eberhardt, P. Laheurte, Mater. Sci. Eng. C 38, 151 (2014)

10. L.M. da Silva, A.P. Rosifini Alves Claro, M.A.R. Buzalaf, C.R. Grandini, Mater. Res. 15, 355 (2012)

11. L. Mohan, C. Anandan, V.K. William Grips, J. Mater. Sci. Mater. Med. 24, 623 (2013)

12. Z. Cai, G. Zhang, Y. Zhu, M. Shen, L. Wang, M. Zhu, Tribol. Int. 59, 312 (2013)

13. E. Vasilescu, P. Drob, D. Ionita, S. Ivanescu, C. Vasilescu, Int. J. Environ. Sci. Dev. 1, 31 (2010)

14. K. Neoh, X. Hu, D. Zheng, E. Kang, Biomaterials 33, 2813 (2012)

15. S. Subramaniam, Y. Fang, S. Sivasubramanian, F. Lin, C. Lin, Biomaterials 74, 99 (2016)

16. T.R. Rautray, R. Narayanan, K. Kim, Prog. Mater. Sci. 56, 1137 (2011)

17. J.C.M.J. Pivin, F. Pons, J. Takadoum, H.M. Pollock, G. Farges, J. Mater. Sci. 22, 1087 (1987)

18. M. Ueda, M.M. Silva, C. Otani, H. Reuther, M. Yatsuzuka, C.M Lepienski, L.A. Berni, Surf. Coat. Technol. 169-170, 408 (2003)

19. D. Krupa, E. Jezierska, J. Baszkiewicz, M. Kaminski, T. Wierzchon, A. Barcz, Surf. Coat. Technol. 79, 240 (1996)

20. R. Hutchings, Mater. Sci. Eng. 69, 129 (1985)

21. G.S. Savonova, M. Ueda, R.M. Oliveira, C. Otania, Surf. Coat. Technol. 206, 2017 (2011)

22. R. Asokamani, R. Balu, N. Bhuvaneswaran, U.K. Mudali, in Proceedings of seventh international symposium on electrochemical methods in corrosion research (EMCR), Hungary, 2000, p. 110

23. D. Krupa, J. Baszkiewicz, E. Jezierska, J. Mizera, T. Wierzchon, A. Barcz et al., Surf. Coat. Technol. 111, 86 (1999)

24. X. Feng, G. Tang, X. Ma, M. Sun, L. Wang, Nucl. Instr. Methods Phys. Res. B 301, 29 (2013)

25. J. Chaumont, F. Lalu, M. Salomé, A.M. Lamoise, H. Bernas, Nucl. Instr. Methods B 9, 344 (1981)

26. J.P. Biersack, L.G. Hazgmark, Nucl. Instr. Methods 174, 257 (1980)

27. J.P. Biersack, Nucl. Instr. Methods 182-183, 199 (1981)

28. P. Stempfle, J. Takadoum, Tribol. Int. 48, 35 (2012)

29. A. Domatti, P. Stempfle, P. Carrière, J. Takadoum, Tribol. Lett. 51, 207 (2013)

30. Y. Miyagawa, S. Nakao, K. Baba, R. Hatada, M. Ikeyama, S. Miyagawa, Surf. Coat. Technol. 103-104, 323 (1998)

31. S. Drob, V. Cora, P. Drob, E. Vasilescu, D. Gordin, T. Gloriant, J. Miner. Metals Mater. Soc. 67, 818 (2015)

32. J. Qu, P.J. Blau, T.R. Watkins, O.B. Cavin, N.S. Kukarni, Wear 258, 1348 (2005)

33. C.X. Li, J. Xia, H. Dong, Wear 261, 693 (2006)

34. J. Takadoum, C. Roques-Carmes, Surf. Coat. Technol. 52, $153(1992)$

Open Access This article is distributed under the terms of the Creative Commons Attribution License https://creativecom mons.org/licenses/by/4.0 which permits unrestricted use, distribution, and reproduction in any medium, provided the original author(s) and source are credited.

Cite this article as: Stéphanie Carquigny, Jamal Takadoum, Steliana Ivanescu, Comparative study of nitrogen implantation effect on mechanical and tribological properties of Ti-6Al-4V and Ti-10Zr-10Nb-5Ta alloys, Eur. Phys. J. Appl. Phys. 85, 21301 (2019) 